비전 센서를 이용한 쿼드로터형 무인비행체의 목표 추적 제어

유민구*, 홍성경**

\title{
Target Tracking Control of a Quadrotor UAV using Vision Sensor
}

Min Goo Yoo* and Sung Kyung Hong**

\begin{abstract}
The goal of this paper is to design the target tracking controller for a quadrotor micro UAV using a vision sensor. First of all, the mathematical model of the quadrotor was estimated through the Prediction Error Method(PEM) using experimental input/output flight data, and then the estimated model was validated via the comparison with new experimental flight data. Next, the target tracking controller was designed using LQR(Linear Quadratic Regulator) method based on the estimated model. The relative distance between an object and the quadrotor was obtained by a vision sensor, and the altitude was obtained by a ultra sonic sensor. Finally, the performance of the designed target tracking controller was evaluated through flight tests.
\end{abstract}

\section{초 록}

본 논문은 쿼드로터형 무인 비행체를 비전센서를 이용한 목표 추적 위치 제어기 설계하 였고, 이를 시뮬레이션 및 실험을 통해서 확인하였다. 우선 제어기 설계에 앞서 쿼드로터의 동역학 분석 및 실험데이터를 통한 모델링을 수행하였다. 이때, 모델의 계수들은 실제 비행 데이터를 이용한 PEM(Prediction Error Method)을 이용하여 얻었다. 이 추정된 모델을 바탕 으로 LQR(Linear Quadratic Regulator) 기법을 이용한 임의의 목표를 따라가는 위치 제어기 를 설계하였으며, 이때 위치 정보는 비전센서의 색 정보를 이용한 Color Tracking기능을 이 용하여 쿼드로터와 물체의 상대적인 위치를 얻어내었고, 초음파 센서를 이용하여 고도 정 보를 얻어 내었다. 마지막으로 실제 움직이는 물체의 추적 제어 실험을 수행하여 LQR 제 어기 성능을 평가하였다.

Key Words : Quadrotor(쿼드로터), Prediction Error Method(PEM, 예측오차기법), Target Tracking Control(목표 추적 제어), Vision Sensor(비전센서), LQR(Linear Quadratic Regulator)

† 2011년 12월 6일 접수 2012년 1월 20일 심사완료

* 정회원, 세종대학교 항공우주공학과 대학원

** 정회원, 세종대학교 항공우주공학과 교신저자, E-mail: skhong@sejong.ac.kr 서울시 광진구 군자동 98

\section{I. 서 론}

최근 재난감시, 환경감시, 정찰 등을 위한 무 인비행기(UAV, Unmanned Aerial Vehicle)에 관 한 연구가 활발하게 진행되고 있다. 특히, 이러한 비행 로봇 중에서 쿼드로터형 무인비행체는 회전 
익형 비행체로서 VTOL(Vertical Take-off and Landing, 수직이착륙), 전 방향 이동 및 호버링 (Hovering, 정지비행)이 가능하고, 동축 반전형 및 싱글 로터형 등 다른 형식에 비해 구조가 간 단하다[1]. 이러한 장점으로 인하여, 국내외 대학 에서 실내외 자율 비행을 위한 쿼드로터 비행체 에 대한 활발한 연구들이 진행 중이다. 실외 환 경에서는 GPS(Global Positioning System)를 이 용한 유도 항법 제어 및 협동제어[2], 실내 환경 에서는 다중의 카메라를 이용한 위치 인식 시스 템 Vicon Motion Capture System이나 Laser Rangefinder를 이용하여 실내 mapping 및 쿼드 로터의 실내 위치 제어 및 물체 회피에 대한 연 구가 진행되고 있다[3,4]. 그러나 위의 연구들은 실외 환경에서는 GPS에 대해 매우 의존적이며, 실내 환경에서는 위치 인식 시스템의 고가의 시 스템 환경 구축, 공간의 제약성으로 인하여 한정 적이며 활용도가 낮다.

본 연구에서는 실내외 유도 제어에 앞서, 기존 연구들을 고려하여 공간의 제약성을 무시하고, 그 활용도를 높인 시각 기반의 시스템을 구성하 여 움직이는 물체 추적 제어를 연구 목표로 한 다. 구성한 시각기반 시스템은 쿼드로터의 탑재 중량을 고려하여 가볍고, 저가의 움직이는 물체 를 인식하는 시스템을 구성하였다. 이러한 시각 기반의 물체 인식 시스템은 물체의 색 정보를 이 용한 Color Tracking방법으로 물체를 인식하였 다. 또한, 본 연구 목표를 위해 이미 자세 안정화 가 되어 있고, 접근성이 쉬운 상용 쿼드로터 플 랫폼을 이용하였다.

우선 제어기 설계에 앞서 쿼드로터 모델의 동 역학 분석 및 실험데이터를 통한 모델링을 하였 다. 이때, 모델의 계수들은 실제 시스템의 입력, 출력 비행 데이터를 이용한 PEM(Prediction Error Method)을 이용하여 얻었으며, 새로운 실험 데 이터와의 비교를 통하여 모델을 입증하였다. 이 추정된 모델은 목표 추적 제어를 위해 선형화된 상태 공간 형태의 시스템으로 구성하고, 이 모델 을 기반으로 LQR(Linear Quadratic Regulator)기 법을 이용한 임의의 목체를 따라가는 위치 제어 기를 설계하였다. 마지막으로 실험을 수행하여 설계된 제어기 성능을 평가하였다.

\section{II. 시스템 및 실험 환경 구성}

시스템 구성은 크게 2가지로 나눌 수 있다. 첫 번째는 위치를 측정하는 센서, 쿼드로터, 비행 제

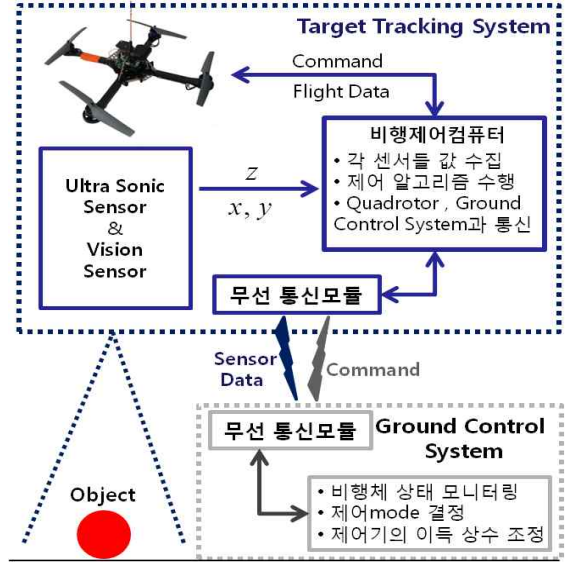

그림 1. 시스템 구성도

어 알고리즘을 수행하는 비행제어컴퓨터(Flight Control Computer, FCC)로 구성되어 있는 목표 추적 시스템(Target Tracking System)이다. 두 번 째는 목표 추적 시스템으로부터 비행체 상태를 모니터링하고, 제어기의 이득 상수 등을 조정하 며, 비행 모드를 관장하는 지상관제 시스템 (Ground Control System)으로 구성된다.

\section{1 쿼드로터 시스템}

본 연구에서 사용된 쿼드로터는 연구 목적으 로 많이 사용되어지는 Ascending Technology社 의 Hummingbird Autopilot System을 사용하였 다. 이 쿼드로터 시스템은 구조적으로 추가적인 센서나 제어기 등을 탑재할 수 있도록 설계되어 있으며, 충돌로 인하여 기체가 손상이 되었을 때 쉽게 교체 및 수리를 할 수 있다. 또한 이 쿼드 로터는 롤 $(\phi)$ 각, 피치 $(\theta)$ 각, 요 각속도 $(\dot{\psi})$ 에 대한 on-board형태의 $1 \mathrm{kHz}$ 속도의 자세 제어기가 탑 재 되어 있어, 조종하기가 쉽다[5]. 이 시스템의 인터페이스는 RC 조종기 입력이나 무선통신 모 듈을 이용하여 입력 및 출력을 제어할 수 있으므 로 본 논문의 목표인 움직이는 물체에 대한 추적 제어에 대하여 적합한 플랫폼이다. 간단한 제원 은 표 1 과 같다.

표 1. 쿼드로터 시스템의 제원

\begin{tabular}{cc}
\hline \hline 중량 & $0.550 \mathrm{~kg}$ \\
\hline 추가 탑재 중량 & $0.200 \mathrm{~kg}$ \\
\hline 최대 반경 크기 & $0.600 \mathrm{~m}$ \\
\hline 최대 비행시간 & 20 분 \\
\hline 순항 속도 & $36 \mathrm{~km} / \mathrm{h}$ \\
\hline On-board Sensor & $\mathrm{MEMS} \mathrm{IMU,} \mathrm{GPS,} \mathrm{Compass}$ \\
\hline \hline
\end{tabular}




\section{2 목표 추적 시스템}

목표 추적 시스템에서는 그림 1 에서 볼 수 있 듯이, 고도 및 위치 정보를 알려주는 센서들과 쿼드로터와 통신 및 비행 제어 알고리즘을 수행 하는 비행제어컴퓨터로 구성되어 있다.

\subsection{1 물체 위치 인식 시스템}

물체의 상대적 고도 측정을 위해서 초음파 센 서를 사용하였다. 또한 고도는 지평면으로부터의 수직 고도로써, 초음파 센서로부터 거리 $h^{\prime}$ 로부 터 쿼드로터의 자세 틀어짐을 보상하는 다음의 식(1)의 $h$ 를 사용한다.

$$
h=h^{\prime} \cos \theta \cos \phi
$$

움직이는 물체를 인식하고 비행체와 물체간의 상대적 거리를 측정하는 시스템은 CMUcam이라 는 비전 센서를 이용하였다. 이 센서는 소형의 CMOS(Complementary Metal Oxide Semiconductor) 카메라와 영상신호를 필터링하고 Serial통 신으로 이 장치와 통신을 가능하게 하는 연산장 치로 구성되어 있다. 이 센서의 특징은 연속된 두 개의 장면에서의 화소간의 차이를 검출하는 장면 차분(Frame Differencing), 한 화면에서 특 정한 색의 위치를 찾는 색 추적(Color Tracking) 과 같은 기능을 가지고 있다[6]. 본 논문에서는 이러한 기능들 중에서 움직이는 물체의 위치 인 식을 위해서 Color Tracking(색 추적)기능을 이 용하여 물체의 상대적 거리를 측정하였다.

이 비전 센서는 적색, 녹색, 청색을 혼합하여 색을 나타내는 방식의 RGB(Red, Green, Blue), 휘도(빛의 광도)와 적색 채도, 청색 채도를 혼합 하여 색을 나타내는 방식인 $\mathrm{YCrCb}$ (Illumination, Chroma Red, Chroma Blue) Color Space로 Color Tracking을 할 수 있다. 그림 2는 실제로 흰색 바탕에 청색 물체를 올려놓고, $\mathrm{RGB}$ 와 $\mathrm{YCrCb}$ 영역에서 촬영한 예이다.
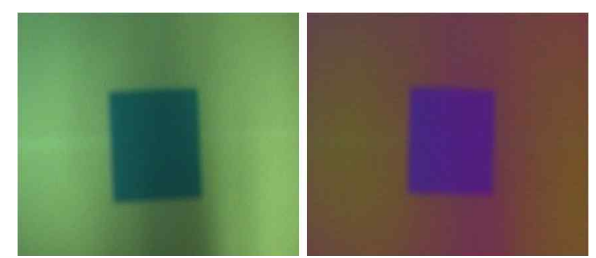

그림 2. $\mathrm{RGB}$ (좌), $\mathrm{YCrCb}$ (우)

실제로 사용된 비전 센서에서는 임의의 정해 진 색의 허용오차(tolerance)를 정해 놓고 Color
Tracking을 한다. 다음의 그림 3 은 빛의 영향을 보기 위해 $10 \%$ 의 허용오차 안에서의 청색의 분 포를 나타낸 그림이다.

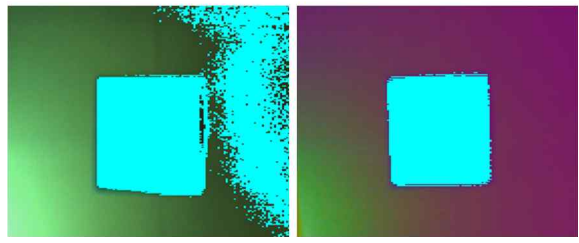

그림 3. 광량의 영향에 따른 청색분포(10\% 허용오차) $\mathrm{RGB}$ (좌), $\mathrm{YCrCb}$ (우)

그림 3에서 보면, 같은 허용 오차 영역에서 $\mathrm{RGB}$ 방식 보다는 $\mathrm{YCrCb}$ 방식이 빛의 영향을 덜 받는 것을 알 수 있었다. 이 결과를 바탕으로 YCrCb방식으로 Color Tracking을 이용하였다. 비전 센서를 이용하여 움직이는 물체와 쿼드로 터와의 거리를 측정하기 위해서는 다음 그림 4 와 같은 기하학적 관계로부터 위치를 알 수 있다.

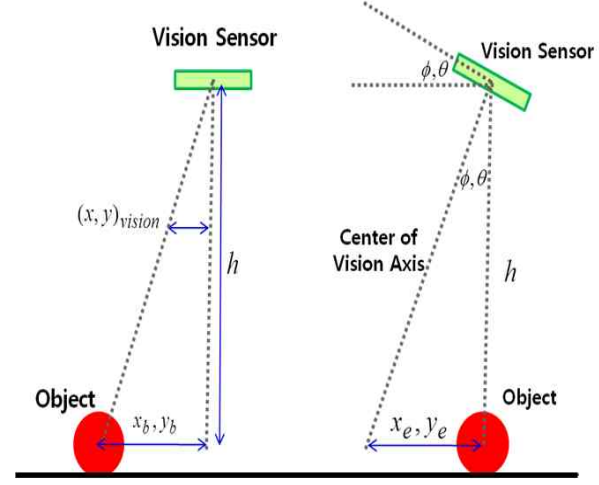

그림 4. 높이 및 틀어짐에 따른 물체 위치의 기학학적 관계

여기서 $(x, y)_{v i s i o n}$ 는 실제로 비전 센서로부터 얻어진 상대적 위치 값이고, $h$ 는 물체와 센서와 의 수직 거리이며, $x_{e}, y_{e}$ 는 비전 센서의 각도 틀 어짐에 따라 생기는 오차 요인, $x_{b}, y_{b}$ 는 실제 상 대적 위치 값이다. $\theta, \phi$ 는 비전 센서의 $x, y$ 축 틀 어진 각도이다. 이는 비전 센서가 쿼드로터 기체 고정 형태로 될 것이므로, 비전 센서의 자세는 쿼드로터의 자세 오일러 앵글과 같다. 이 정보들 을 통해서 $(x, y)_{v i s i o n}$ 을 실제 $x_{b}, y_{b}$ 로 변환하는 식을 구하는 실험을 수행하였다. 실제로 가용되 어질 고도의 범위 및 $\theta, \phi$ 를 고려하여 실험을 수 행하였으며, 그 결과는 다음의 1차 형태의 식 (2)와 와 같으며, 그래프로 본 결과는 그림 5 와 같다. 


$$
\begin{gathered}
x_{b}=\left(x_{\text {vision }}+x_{e}\right) x_{s f} h \\
y_{b}=\left(y_{\text {vision }}+y_{e}\right) y_{s f} h \\
x_{s f}=0.0120, x_{e}=-1.9363 \theta+44.8645 \\
y_{s f}=0.0044, y_{e}=3.7483 \phi+72.2198
\end{gathered}
$$
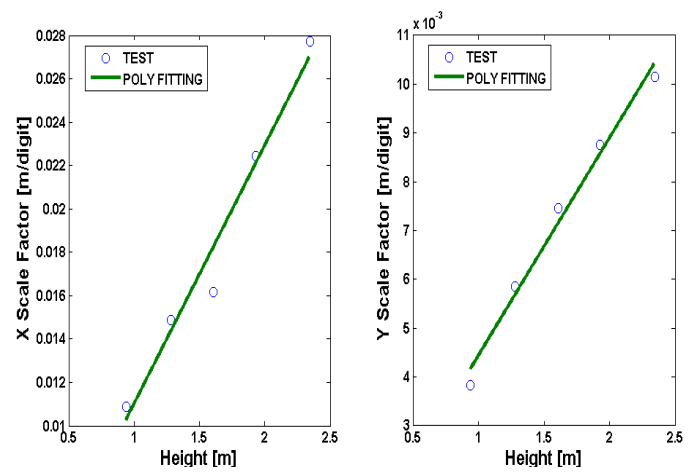

그림 5. 높이에 따른 환산계수 $x$ (좌), $y($ 우 $)$

다음의 그림 6 은 비전 센서의 각도 틀어짐 $\theta$, $\phi$ 에 따른 $x_{e}, y_{e}$ 의 실험 결과이다. 그 결과는 다 선형적인 관계가 나왔다.
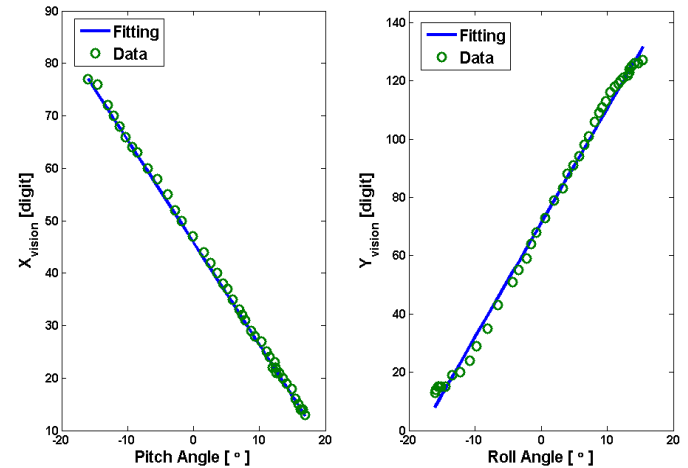

그림 6. 비전 센서의 틀어짐에 따른 $(x)_{\text {vision }}$ (좌), $(y)_{\text {vision }}$ (우)

\subsection{2 비행제어 컴퓨터}

비행제어컴퓨터의 역할은 목표 추적 제어기의 역할을 한다. 쿼드로터에 대한 상대적인 위치 및 고도의 정보, 쿼드로터의 자세 및 가속도의 정보 를 설계된 제어기를 통과하여 쿼드로터에 대한 자세 및 추력 입력을 다시 쿼드로터를 움직이게 한다. 이 때 지상관제 시스템으로부터 입력되어 진 비행체 제어 이득 상수, 자동 또는 수동 비행 전환을 쉽게 바꿀 수 있게 구현하였다. 또한 각 센서들과 무선 송수신 모듈, 쿼드로터의 전원관
리의 역할도 갖는다.

이러한 역할들을 해주는 프로세서는 Texas Instrument社의 TMS320F28335라는 MCU(Micro Controller Unit)을 이용하였다. 이는 각 센서들 로부터 나오는 많은 양의 데이터 처리와 퀴드로 터와 지상관제 시스템 간의 실시간 통신을 하기 에 적합하다. 또한 실수연산이 가능하여 복잡한 실수 연산을 빠르게 처리할 수 있는 장점이 있다 [7]. 그림 7은 사용된 비행제어컴퓨터 보드이다.

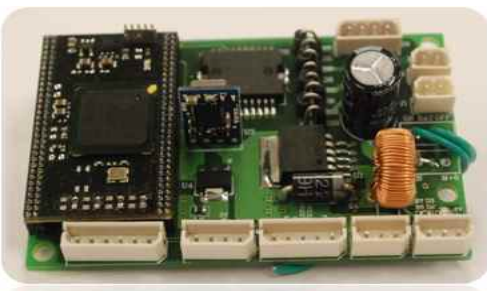

그림 7. 비행제어컴 퓨터

\section{3 지상관제 시스템}

지상관제 시스템은 비행체의 상태를 모니터링 및 제어기의 이득 상수 조정, 자동 또는 수동 비 행의 전환의 역할을 한다. 이와 같은 시스템을 구축하면, 비행체의 상태(power 부족 또는 자체 결함) 결함 문제를 실시간으로 모니터링 할 수 있다[8]. 이를 위해서 dSPACE社의 DS1401이라 는 실시간 컴퓨터(Real Time Computer)를 이용 하였다[9]. 실시간 컴퓨터 DS1401은 단독적으로 구동이 되지 않고, Host 컴퓨터의 MathWorks社 의 MATLAB/SIMULINK, GUI기반의 Control Desk 소프트웨어와 연동이 되어 구동이 된다. 아 래의 그림 8 은 지상관제 시스템의 구성도이다.

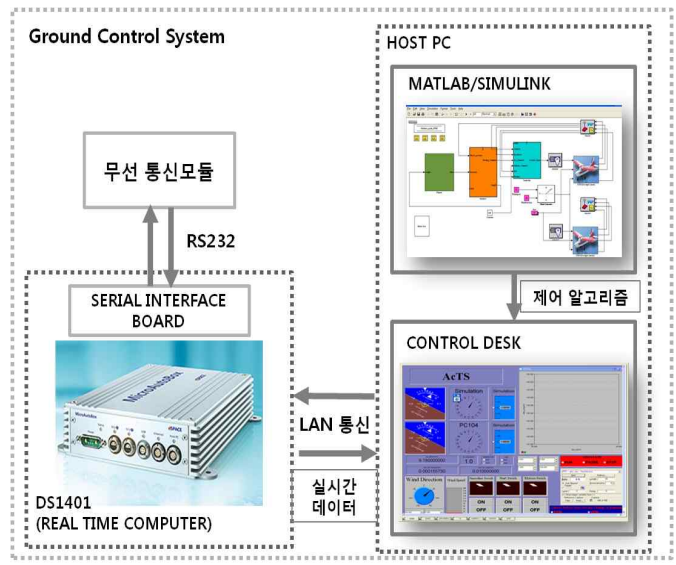

그림 8. 지상관제 시스템 


\section{III. 쿼드로터의 동적 모델 추정}

쿼드로터는 비선형성, 여러 외란, 센서의 노이 즈 등이 혼합되어진 시스템이다. 본 논문에서는 이러한 시스템의 신뢰성 높은 모델을 얻기 위해 실제 시스템의 입력 및 출력 자료를 이용하는 예 측오차기법(Prediction Error Method)을 통해서 모델을 추정하였으며, 새로운 실험 데이터와 예 측되어진 모델과의 비교를 통해서 검증하였다.

\subsection{System Identification(시스템 식별)}

\subsubsection{System Identification 실험 구성}

System Identification실험을 위해서 시스템의 입출력 데이터는 무선 통신모듈을 이용하여 지상 과 송수신 하였고, 지상에서는 입력 및 출력 데 이터를 실시간 컴퓨터를 통해서 $10 \mathrm{~Hz}$ 속도로 데 이터 수집을 하였다. 이때 바람과 같은 외란이 고려되지 않게 하기 위하여 실내에서 실험을 수 행하였다. 쿼드로터 시스템의 입력은 RC 조종기 의 입력(롤 및 피치 각 입력, 요축 각속도 입력, 4 개 프로펠러에 대한 추력 입력)이며, 출력은 조 종기 입력에 대한 출력(롤 및 피치 각, 요축 각 속도, 전체 추력 변화량)이다. 다음의 그림 9는 실험 구성도이다.

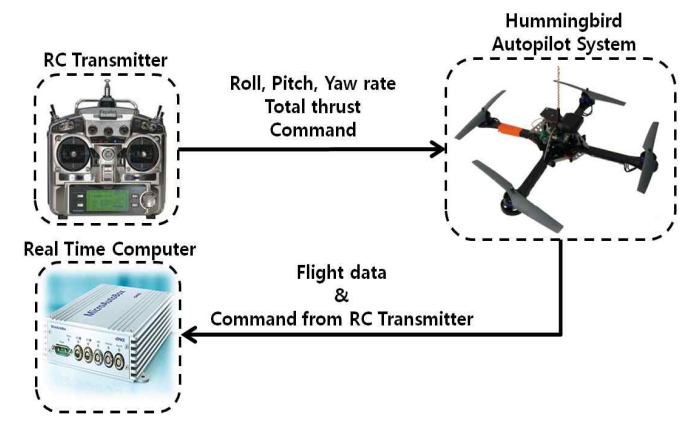

그림 9. System Identification 실험 구성

\subsection{2 시스템 구조 결정}

쿼드로터는 크기가 작고, 상하좌우의 형태가 비교적 대칭적인 형태이므로 쿼드로터를 하나의 질점 모델로 생각할 수 있다[10]. 또한 쿼드로터 의 질량이 변함없고, 쿼드로터에 중력과 추력만 이 존재한다면 뉴턴의 제 2 법칙을 이용하여 다음 식(3),(4)과 같이 유도할 수 있다.

$$
\ddot{r}_{I}=\frac{1}{m} R_{I B}(\phi, \theta, \psi)\left[\begin{array}{c}
0 \\
0 \\
-T
\end{array}\right]+\left[\begin{array}{l}
0 \\
0 \\
g
\end{array}\right]
$$

$$
R_{I B}(\phi, \theta, \psi)=
$$

$$
\left[\begin{array}{ccc}
c \theta c \psi & c \theta s \psi & -s \theta \\
s \phi s \theta c \psi-c \phi s \psi & s \phi s \theta s \psi+c \phi c \psi & s \phi c \theta \\
c \phi s \theta c \psi+s \phi s \psi & c \phi s \theta s \psi-s \phi c \psi & c \phi c \theta
\end{array}\right]^{T}
$$

$m$ 은 쿼드로터의 질량, $g$ 는 중력가속도, $T$ 는 추력이며, $R_{I B}(\phi, \theta, \psi)$ 는 기체 좌표계에서 관성 좌표계로 변환해주는 행렬이다. 이때 식(4)에서의 $c, s$ 는 각각 $\cos , \sin$ 함수를 말한다. 본 논문에서 사용된 쿼드로터는 자세 안정화 기능이 있으므 로, 식(3)에서의 정해지지 않은 변수는 쿼드로터 의 자세 제어기로부터 나오는 출력 오일러 각 및 추력이다. 그러나 내부 자세 제어기의 구조나 정 확한 모델은 알 수 없으므로, 모델은 그림 10 과 같이 분리 되어진 롤 $(\phi)$, 피치 $(\theta)$, 요 각속도 $(\dot{\psi})$, 추력( $T)$ 에 대한 선형 1차로 가정하였다[11]. 여 기서 출력에서의 추력은 프로펠러로부터 나오는 중력의 영향이 없는 순수 추력을 말한다.

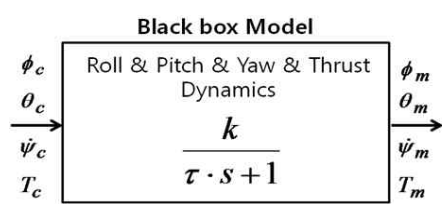

그림 10. 자세 제어기 모델

\subsection{3 모델의 추정}

앞서 가정한 1 차 형태의 자세 안정화 제어기 모델의 계수들은 예측 오차 기법을 통하여 구했 다. 이는 실제 시스템의 출력과 가상의 모델의 출력과의 오차를 추정 알고리즘을 통해서 모델을 추정하는 것이다. 자세한 과정은 다음과 같다. 우 선, 일반적인 선형 시스템의 모델은 식(5)과 같이 선형 예측변수 모델(Linear Predictor Model)로 가정할 수 있다[12].

$$
\hat{y}(t)=\hat{G}(q, \Theta) u(t)+\hat{H}(q, \Theta) e(t)
$$

여기서 $\hat{G}$ 는 시스템의 예상되는 동적 특성을 나타내고 $\hat{H}$ 은 예상되는 외란이나 잡음특성, $q$ 는 지연 연산자(delay operator), $\Theta$ 는 구하고자 하는 모델 계수의 벡터이며, $e$ 는 측정 잡음 (white noise), $u$ 는 실제 입력 값, $\hat{y}$ 는 가상의 모 델의 출력 값이며, 예측된 출력 값이다.

예측 오차 기법은 최소 자승 반복법을 이용하 여 비용 함수 $V(\hat{G}, \hat{H})$ 를 최소화하여 모델의 계 수를 구하며, 식(6)과 같다. 


$$
V(\hat{G}, \hat{H})=\sum_{i=1}^{N} \epsilon^{2}(t)
$$

이 때, $\epsilon$ 은 추정된 모델로부터 나온 출력 값과 실제 측정값과의 오차를 말하며, 식(7)과 같이 다 시 표현할 수 있다.

$$
\epsilon(t)=y(t)-\hat{y}(t)=\hat{H}^{-1}[y(t)-\hat{G} u(t)]
$$

$\epsilon$ 는 결국, 측정 잡음 $e$ 와 같다고 볼 수 있으 며[13], 이 측정치와 추정치사이의 오차를 추정하 여 모델을 추정한다. 이 모델의 계수들을 추정하 기 위해서 MathWorks社의 MATLAB/Parameter Identification Tool을 이용하였다[14].

모델 추정을 위한 실험은 총 8 번을 수행하였 고, 그 결과는 표 2 와 같다. 각각의 모델은 다른 입출력 데이터들과 비교를 통해서 백분율 단위의 표준 편차로써 그 결과를 표현하였다. 각 시스템 의 입력단위는 $\mathrm{RC}$ 조종기에서부터 나오는 디지털 값이며, 출력 단위는 롤, 피치, 요축의 모델의 경 우에는 ${ }^{\circ}, \mathrm{sec}$ 단위이고, 추력 모델은 중력가 속도 $\left(\mathrm{m} / \mathrm{sec}^{2}\right)$ 의 단위이다.

표 2. 모델 추정 결과

\begin{tabular}{cccc}
\hline \hline 모델 & 전달함수 & $K$ 표준편차 [\%] & $\tau$ 표준편차 [\%] \\
\hline$\frac{\phi}{\phi_{c}}$ & $\frac{0.0142}{0.0945 s+1}$ & 10.4355 & 16.5409 \\
\hline$\frac{\theta}{\theta_{c}}$ & $\frac{0.0138}{0.1034 s+1}$ & 13.8338 & 18.2837 \\
\hline$\frac{\dot{\psi}}{\dot{\psi}_{c}}$ & $\frac{-0.0038}{0.2691 s+1}$ & 3.9576 & 6.0773 \\
\hline$\frac{T}{T_{c}}$ & $\frac{-0.0063}{0.0011 s+1}$ & 8.3830 & 0.6350 \\
\hline \hline
\end{tabular}

\section{2 모델의 입 증}

모델 입증을 위해 총 4 번의 실험을 수행하였 고, 이를 추정된 모델과 비교를 하였다. 아래의 표 3은 실제 출력 값과 시뮬레이션을 통한 모델 의 출력 값과의 정확도를 나타내었다.

표 3. 모델 입증 결과

\begin{tabular}{ccccc}
\hline \hline$\#$ & $\phi$ 모델 [\%] & $\theta$ 모델 [\%] & $\dot{\psi}$ 모델 [\%] & $T$ 모델 [\%] \\
\hline 1 & 84.23 & 88.76 & 87.09 & 68.80 \\
\hline 2 & 83.72 & 88.24 & 87.16 & 68.69 \\
\hline 3 & 82.88 & 88.68 & 87.20 & 67.70 \\
\hline 4 & 83.52 & 88.74 & 86.81 & 68.48 \\
\hline \hline
\end{tabular}
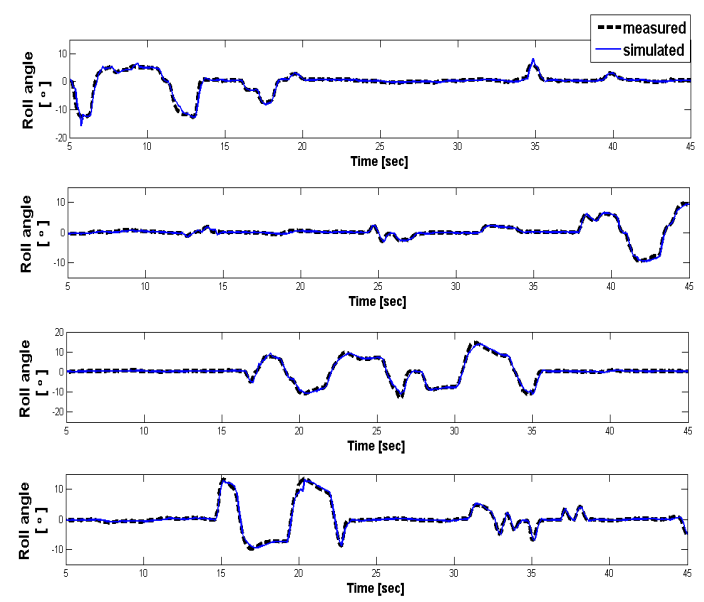

그림 11. 롤 $(\phi)$ 모델 추정 결과
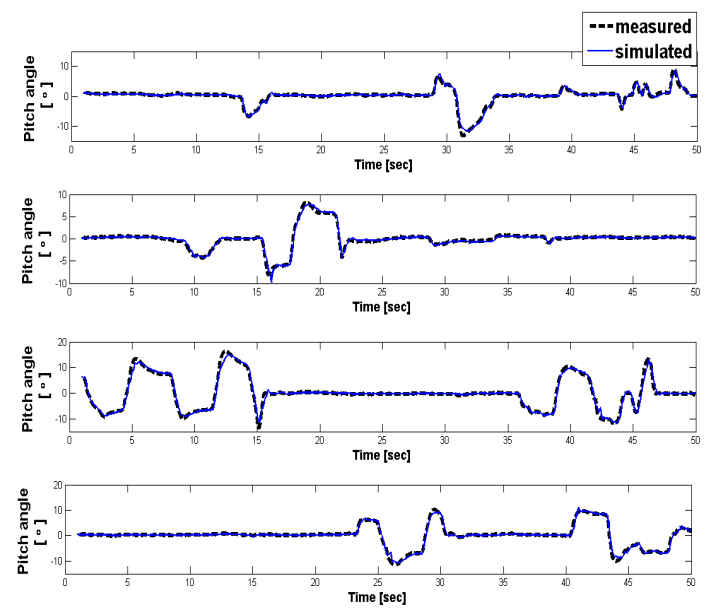

그림 12. 피치 $(\theta)$ 모델 추정 결과
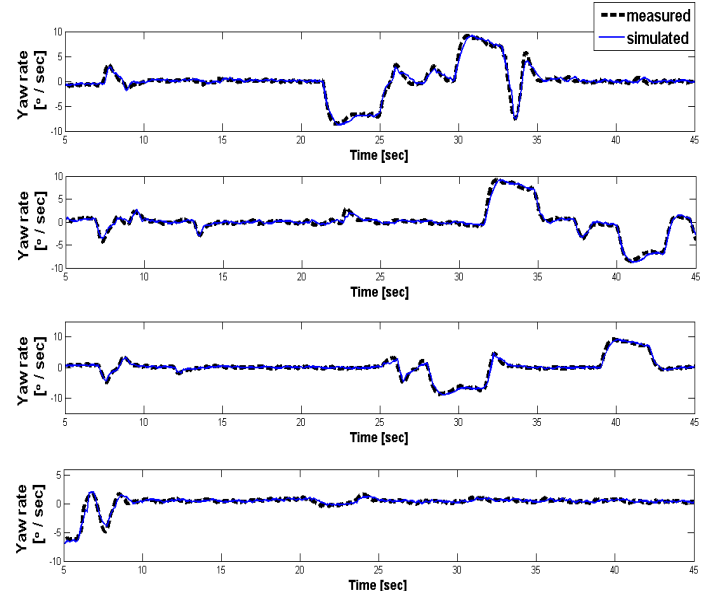

그림 13. 요 각속도 $(\dot{\psi})$ 모델 추정 결과 

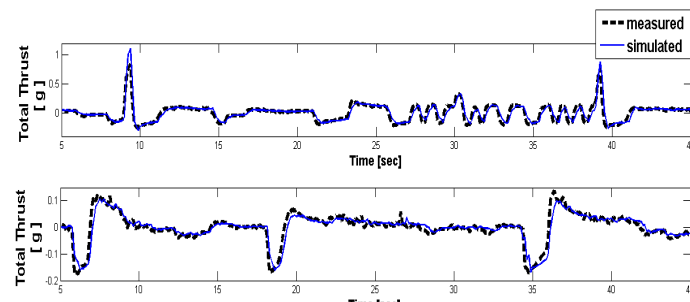

Time [seq
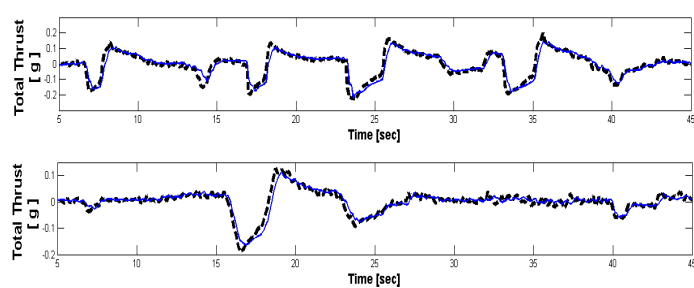

그림 14. 추력 $(T)$ 모델 추정 결과

IV. 목표 추적을 위한 제어기 설계
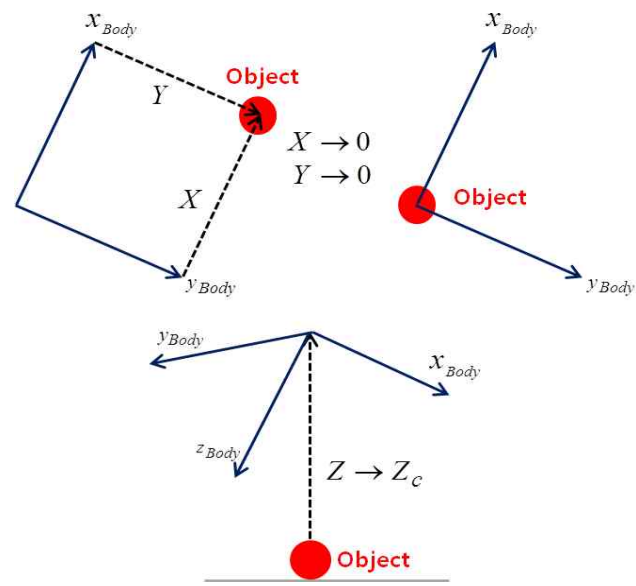

그림 15. 물체 추적 방법

앞서 쿼드로터의 추정된 모델을 기반으로 움 직이는 물체의 추적은 물체 추적 방법은 $X Y$ 평 면상에서 생각해보면 쿼드로터와 물체와의 상대 적 거리가 생겼을 때, 그 거리 $(X, Y)$ 를 0 으로 만 들고, 물체와 고도 $(Z)$ 를 어떠한 일정한 고도로 유지하는 것을 목표로 한다. 이때 $X, Y$ 는 비전 센서로부터 나오는 식(3)의 $x, y$ 로부터 구해지며, $Z$ 는 지평면으로부터의 수직 고도로써, 초음파 센서로부터 식(1)에 의해 구해진다.

\section{1 목표 추적 제어를 위한 동적 모델}

제어기 설계 앞서, 추정 되어진 자세 안정화 제어기 모델과 식(3)을 합쳐서 상태 공간 형태의
모델을 유도하였다. 이때 방위각 $(\psi)$ 은 0 으로 생 각하였다. 이는 앞서 설명한 물체를 추적방법에 서 방위각 $(\psi)$ 은 고려하지 않아도 되므로, 롤 $(\phi)$ 각, 피치 $(\theta)$ 각에 대해서만 좌표변환을 한다. 모델 은 3축 $(X, Y, Z)$ 으로 나누어서 모델을 구성하였 다. 이는 각 축이 각각의 상태 변수에 대하여 독 립적이라는 가정 아래 유도하였으며, 상태 변수 는 다음과 같다.

$$
X:\left[\begin{array}{lll}
X & \dot{X} & \theta
\end{array}\right]^{T}, Y:\left[\begin{array}{lll}
Y & Y & \phi
\end{array}\right]^{T}, Z:\left[\begin{array}{lll}
Z & Z & Z
\end{array}\right]^{T}
$$

여기서 $X, \dot{X}, Y, \dot{Y}$,는 쿼드로터와 물체의 상 대적인 위치이고, 각각의 입력은 $\theta_{c}, \phi_{c}, T_{c}$ 이다. 먼저 $X, Y$ 축은 롤 $(\phi)$ 각, 피치 $(\theta)$ 각에 대해서만 좌표변환을 하면 다음과 같이 쓸 수 있다.

$$
\ddot{X}=-\frac{T}{m}(\sin \theta \cos \phi), \ddot{Y}=-\frac{T}{m}(-\sin \phi)
$$

여기서 $\phi \approx 0, \theta \approx 0, T \approx m g$ 라고 가정한다 면 식(10)과 같이 표현할 수 있다.

$$
\ddot{X}=-g \theta, \ddot{Y}=g \phi
$$

이를 통해서 표 3-1에서의 롤 $(\phi)$, 피치 $(\theta)$ 모델 의 전달함수의 분모항의 계수를 정상 상태 오차 가 없다고 고려하여 1 이라고 가정하고, 식(8)에서 정의한 상태 변수를 바탕으로 외란이 없다고 가 정한다면, 식(11)과 같이 상태 공간 형태의 모델 로 표현할 수 있다.

$$
\begin{aligned}
& A_{X}=\left[\begin{array}{ccc}
0 & 1 & 0 \\
0 & 0 & 0 \\
0 & 0 & \frac{-1}{0.1034}
\end{array}\right], B_{X}=\left[\begin{array}{c}
0 \\
-g \\
\frac{1}{0.1034}
\end{array}\right] \\
& A_{Y}=\left[\begin{array}{ccc}
0 & 1 & 0 \\
0 & 0 & 0 \\
0 & 0 & \frac{-1}{0.0945}
\end{array}\right], B_{Y}=\left[\begin{array}{c}
0 \\
g \\
1 \\
\hline 0.0945
\end{array}\right] \\
& C_{X}=C_{Y}=\left[\begin{array}{lll}
1 & 0 & 0 \\
0 & 0 & 0 \\
0 & 0 & 1
\end{array}\right], D_{X}=D_{Y}=\left[\begin{array}{l}
0 \\
0 \\
0
\end{array}\right]
\end{aligned}
$$

$Z$ 축의 모델은 $X, Y$ 축 모델과 비슷하게 표 2에 서의 추력 $(T)$ 모델에서 정상 상태 오차가 없다고 가정한 뒤 2 번 적분한 모델로 유도하였다.

$$
\frac{Z}{T_{c}}=\frac{-1}{s^{2}(0.0010 s+1)}=\frac{-1}{0.0011 s^{3}+s^{2}}
$$

이 모델을 다시 상태 공간 형태의 모델로 표 현하면 식(13)과 같다. 


$$
\begin{aligned}
A_{Z} & =\left[\begin{array}{ccc}
0 & 1 & 0 \\
0 & 0 & 1 \\
0 & 0 & \frac{-1}{0.0011}
\end{array}\right], B_{Z}=\left[\begin{array}{c}
0 \\
0 \\
\frac{1}{0.0011}
\end{array}\right] \\
C_{Z} & =\left[\begin{array}{lll}
1 & 0 & 0 \\
0 & 0 & 0 \\
0 & 0 & 1
\end{array}\right], D_{Z}=\left[\begin{array}{l}
0 \\
0 \\
0
\end{array}\right]
\end{aligned}
$$

상태변수 $\ddot{Z}$ 은 가속도계에서 측정된 값을 중 력 성분을 제외 한 관성좌표계에서의 가속도 값 을 이용하였다.

위의 모델에서 보면, 센서의 부재로 인하여 상 태변수 $\dot{X}, \dot{Y}, \dot{Z}$ 는 측정되지 않는다. 본 논문에서 는 상태 공간 제어설계(state-space control design)법을 이용한 제어가 목표이므로, 측정 되 지 않는 $\dot{X}, \dot{Y}, \dot{Z}$ 상태변수를 구하는 과정을 4.3 절 에서 설명하겠다.

앞서 구한 $X, Y, Z$ 축의 모델들은 연속적 시간 에서의 모델이다. 그러나 이 모델들을 바탕으로 제어기의 설계는 무리가 있다. 실제로 각 센서들 의 값들을 받는 주기 및 제어기의 출력은 $8 \mathrm{~Hz}$ 이 므로, 연속적 시간에서의 모델을 이산화 하였다. 먼저 이산화 모델의 상태 공간 모델의 정의는 다 음과 같다.

$$
\begin{aligned}
& x_{k+1}=F x_{k}+G u_{k} \\
& y_{k}=H x_{k}+D u_{k}
\end{aligned}
$$

모델의 이산화 방법은 시스템의 입력에 대한 $\mathrm{ZOH}$ (Zero-order Hold)로 이산화를 수행하였고, 그 결과는 다음의 식(15), (16), (17)과 같으며, 행 렬 $H, D$ 는 선형 모델과 같다.

$$
\begin{gathered}
F_{X}=\left[\begin{array}{ccc}
1 & 0.1250 & 0 \\
0 & 1 & 0 \\
0 & 0 & 0.2984
\end{array}\right], G_{X}=\left[\begin{array}{c}
0.0013 \\
0.0214 \\
0.7016
\end{array}\right] \\
F_{Y}=\left[\begin{array}{ccc}
1 & 0.1250 & 0 \\
0 & 1 & 0 \\
0 & 0 & 0.2665
\end{array}\right], G_{Y}=\left[\begin{array}{c}
-0.0013 \\
-0.0214 \\
0.7335
\end{array}\right] \\
F_{Z}=\left[\begin{array}{ccc}
1 & 0.1250 & 0.0001 \\
0 & 1 & 0.0010 \\
0 & 0 & 0
\end{array}\right], G_{Z}=\left[\begin{array}{c}
0.0077 \\
0.1240 \\
1
\end{array}\right]
\end{gathered}
$$

\subsection{LQR (Linear Quadratic Regulator) 제 어기 설계}

쿼드로터 비행체의 목표 추적제어를 위해서 선형 최적제어 이론을 적용하였다. LQR(Linear Quadratic Regulator) 기법을 이용한 제어는 선 형 상태 공간 방정식으로 표현되는 시스템을 이
용하는 최적 제어 기법이다. 본 논문에서는 앞서 이산화 된 상태 공간 방정식을 이용하여 $X, Y, Z$ 축으로 분리된 이산시간(discrete time) LQR제어 기를 설계하였다. $\mathrm{LQR}$ 제어기는 성능 지수 $J$ 를 최소화하는 제어 입력을 결정하는 방법이다. 이 산 시간에서의 성능지수 $J$ 는 식(18)과 같다.

$$
J(u)=\sum_{k=0}^{\infty} x_{k}^{T} Q x_{k}+u_{k}^{T} R u_{k}
$$

$x_{k}$ 는 시스템의 상태 변수이고, $u_{k}$ 는 입력 변수 이다. $Q, R$ 은 가중 행렬로써 설계 변수이다. 여 기서 $Q, R$ 은 다음의 조건을 만족하여야 한다.

$$
Q=Q^{T} \geq 0, R=R^{T} \geq 0
$$

이산 시간 $\mathrm{LQR}$ 제어기의 제어 법칙은 다음의 식(20)과 같고, 제어기의 제어이득 $K$ 는 식(21)과 같이 정의되어진다.

$$
\begin{gathered}
u_{k}=-K x_{k} \\
K=\left[R+G^{T} S G\right]^{-1} G^{T} S F
\end{gathered}
$$

여기서 $S$ 는 식(22)의 $\mathrm{DARE}$ (Discrete-time Algebraic Riccati equation)의 유일해이다.

$F^{T} S G\left[R+G^{T} S G\right]^{-1} G^{T} S F+S-F^{T} S F-Q=0$

실제로 제어이득 상수 $K$ 를 구하기 위해서 MATLAB에서 제공 되어진 dare, dlqro이라는 함 수를 이용하여 구하였다.

실제로 식(10)을 유도하기 위한 $\phi \approx 0, \theta \approx 0$ 라는 가정을 충족하고, 앞서 3.1.3장에서의 모델 추정과정에서 실제 측정되어진 영역에서의 출력 값을 고려하여 시스템의 입력 $\left(\phi_{c}, \theta_{c}, T_{c}\right)$ 을 제한 하였다. 또한 실제 실험에서 존재 가능한 시간지 연을 고려하여 가중 행렬 $Q, R$ 을 적절히 조정 하며 만족할 만한 성능을 보여주는 제어이득 $K$ 를 시뮬레이션을 통하여 구하였다. 또한 $Z$ 축 모 델은 제어기의 입력이 0 이 아닌 기준 입력 $r$ 이 도입이 되므로, 기준 입력 이득 상수 $\bar{N}$ 을 구하 였고[15], 구하는 과정은 식(23)과 같다.

$$
\begin{gathered}
{\left[\begin{array}{l}
N_{x} \\
N_{u}
\end{array}\right]=\left[\begin{array}{cc}
F & G \\
H & D
\end{array}\right]^{-1}\left[\begin{array}{l}
0 \\
1
\end{array}\right]} \\
u=-K x+\left(N_{u}+K N_{x}\right) r \\
\bar{N}=N_{u}+K N_{x}
\end{gathered}
$$




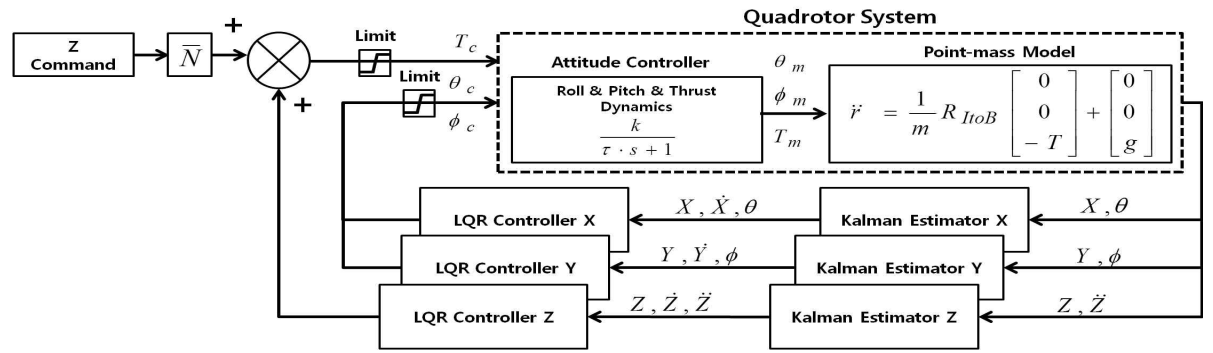

그림 16. 제어기가 추가된 전체적인 시스템 구성도

\section{3 칼만 필터(Kalman Filter)를 이용한 목} 표물과의 상대 속도 추정

비전 센서와 초음파 센서를 이용한 목표의 위 치 인식은 상대적 거리 $X, Y, Z$ 만이 나오며, 상대 속도 $\dot{X}, \dot{Y}, \dot{Z}$ 은 측정이 되지 않는다. 이 측정되 지 않은 상대적 속도를 추정하기 위해서 본 논문 에서는 이산 칼만 필터(Discrete Kalman Filter) 를 이용하였다. 다음의 식(24)은 일반적인 이산 칼만 필터의 구조이다.

$$
\begin{array}{ll}
x_{k+1}=A x_{k}+B u_{k}+G w_{k} & w_{k} \sim N\left(0, Q_{N}\right) \\
y_{k}=H x_{k}+\nu_{k} & \nu_{k} \sim N\left(0, R_{N}\right)
\end{array}
$$

위의 식(24)에서 $w_{k}$ 는 가정 된 시스템 노이즈 로써 평균이 0 이고, 분산이 $Q_{N}$ 인 백색 가우시안 잡음(White Gaussian Noise)이다. 측정 잡음 $\nu_{k}$ 또한 평균이 0 이고 분산이 $R_{N}$ 인 백색 가우시안 잡음으로 정의되어진다.

우선 다음의 식(25)과 같이 상대 거리 $X, Y, Z$ 와 상대 속도 $\dot{X}, \dot{Y}, \dot{Z}$ 을 상태변수로 정하였다.

$$
x_{k}=\left[\begin{array}{llllll}
X_{k} & \dot{X}_{k} & Y_{k} & \dot{Y}_{k} & Z_{k} & \dot{Z}_{k}
\end{array}\right]^{T}
$$

이를 통해서 쿼드로터를 기준으로 물체 속도 는 등속이고, 평균이 0 이고 분산이 0 에 가까운 백색 가우시안 잡음이 섞여 있다고 가정한다면 다음의 식 (26)의 구조로써 표현할 수 있다.

$$
\begin{aligned}
& x_{k+1}=\left[\begin{array}{cc}
1 & \Delta t \\
0 & 1
\end{array}\right] x_{k}+\left[\begin{array}{l}
0 \\
1
\end{array}\right] w_{k} \quad w_{k} \sim N\left(0, Q_{N}\right) \\
& y_{k}=\left[\begin{array}{ll}
1 & 0
\end{array}\right] x_{k}+\nu_{k} \quad \nu_{k} \sim N\left(0, R_{N}\right)
\end{aligned}
$$

여기서 $\Delta t$ 는 샘플링 시간이며, $Q_{N}, R_{N}$ 은 실 제 실험을 통하여 그 값을 정하였다. 결국, 최종 적인 퀴드로터의 시스템 및 $\mathrm{LQR}$ 제어기, 칼만 필 터가추가 된 시스템 구조는 그림 16 과 같다.

\section{V. 제어기 구현 및 실험 결과}

실제 목표 추적 제어기의 검증을 위한 비행 실험에서는 바람과 같은 외란을 덜 받는 실내에 서 실험을 수행하였으며, 쿼드로터의 안전을 위 해서 랜딩기어를 제작 및 가이드를 장착하였다. 아래의 그림 17 은 비행 실험중의 사진이다.

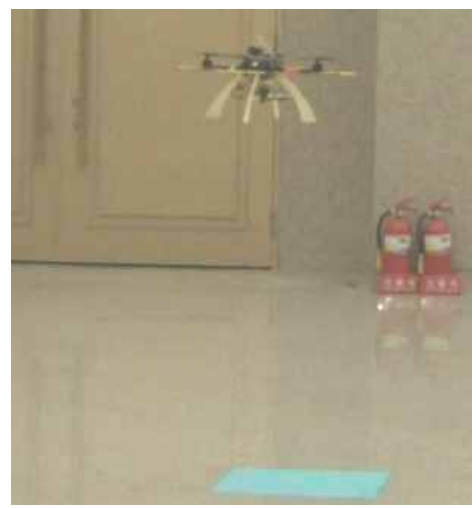

그림 17. 목표 추적 비행 실험

\subsection{Processor In the Loop Simulation}

비행 제어 컴퓨터에 적용된 제어 알고리즘은 앞서 MATLAB/SIMULINK기반의 제어 알고리즘 을 $\mathrm{C}$ 언어로 변환하였다. 이렇게 구현된 제어기 프로그램은 실시간 컴퓨터에서의 제어기의 성능 과 같게 나와야 하므로, 이를 PILS(Processor In the Loop Simulation)를 통해서 제어 프로그램을 검증하였으며, 다음의 그림 18은 PILS 구성도이 다[16]. 그림 18 과 같이 위치 및 쿼드로터의 상태 데이터를 받아서 비행제어 컴퓨터와 Real Time Computer에서 계산된 제어기의 출력 값 $\left(T_{c}, \phi_{c}, \theta_{c}\right)$ 을 비교하였으며, 그 결과는 다음의 그 림 19 와 같다. 아래의 결과는 수동 비행 중에 계 산된 제어기 출력 값과 비교하였다. 


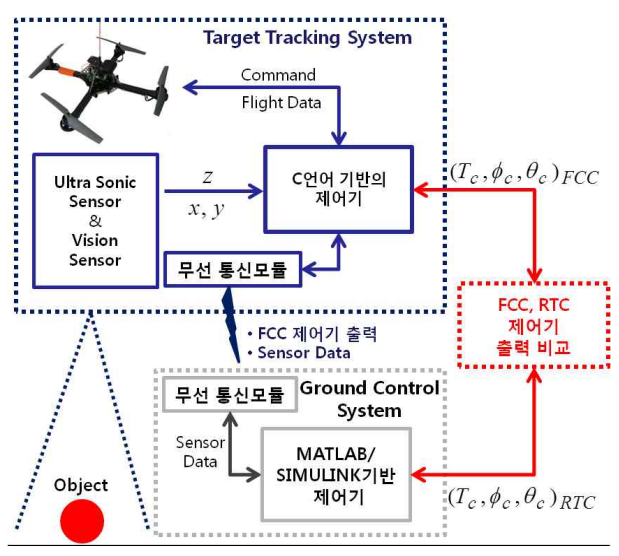

그림 18. PILS 구성도
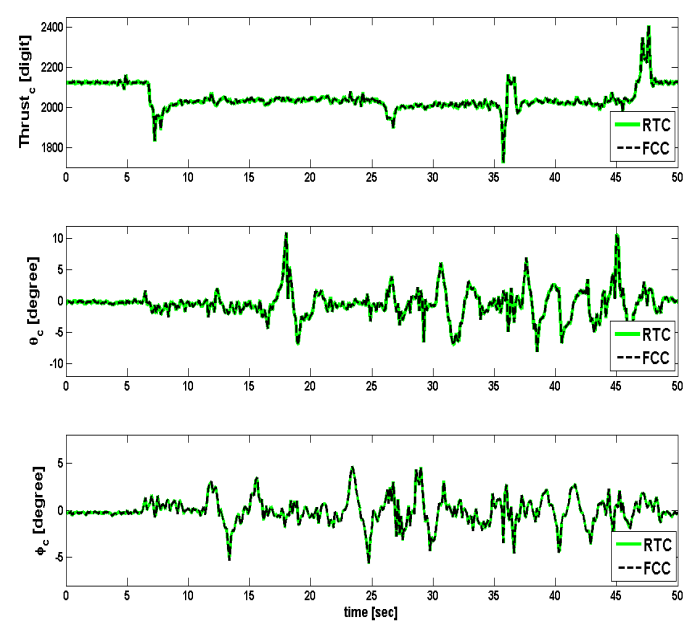

그림 19. PILS 결과

\section{2 목표 추적 제어 결과}

목표 추적 제어 실험을 수행하는 동안에 실제 로 목표물을 약 $0.2 \mathrm{~m} / \mathrm{sec}$ 등속도로 임의의 방향 으로 움직였다. 그 결과는 다음의 그림 20, 21, 22 와 같다. 그림 20,21 은 $X, Y$ 축의 각각의 상태 변수들을 도시하였으며, 그림 22는 목표 추적을 하는 동안에 $Z$ 축 상태 변수들 결과이다. $Z$ 축에 서의 고도는 $1.6 \mathrm{~m}$ 의 고정된 값으로 목표 추적 제어 실험을 수행하였다.

$X, Y$ 축 결과를 살펴보면, 상대적 위치는 약 $\pm 0.15 \mathrm{~m}$ 의 오차 영역 안에 들어와 있다. 또한 물 체와의 상대적 고도는 $\pm 0.1 \mathrm{~m}$ 오차 영역 안에서 제어가 되었다. 이때 실제 제어 입력 $\left(T_{c}, \phi_{c}, \theta_{c}\right)$ 은 각각 $\pm 10 \mathrm{~m} / \mathrm{sec}^{2}, \pm 10^{\circ}$ 로 제한하였고, 그 결 과는 제한한 영역 안으로 들어온 것을 확인할 수 있었다.
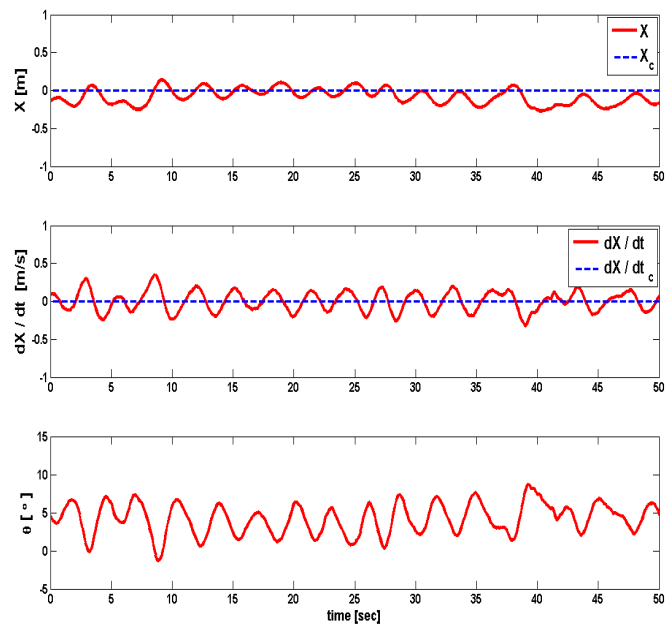

그림 20. $X$ 축 실험 결과
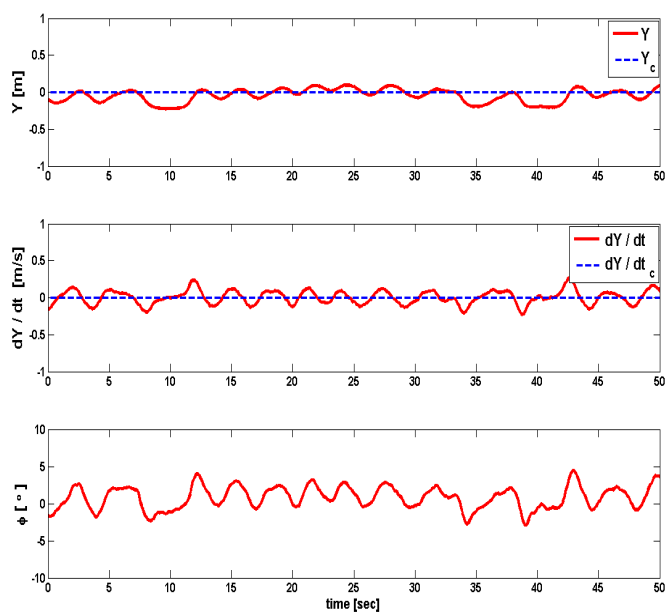

그림 21. $Y$ 축 실험 결과
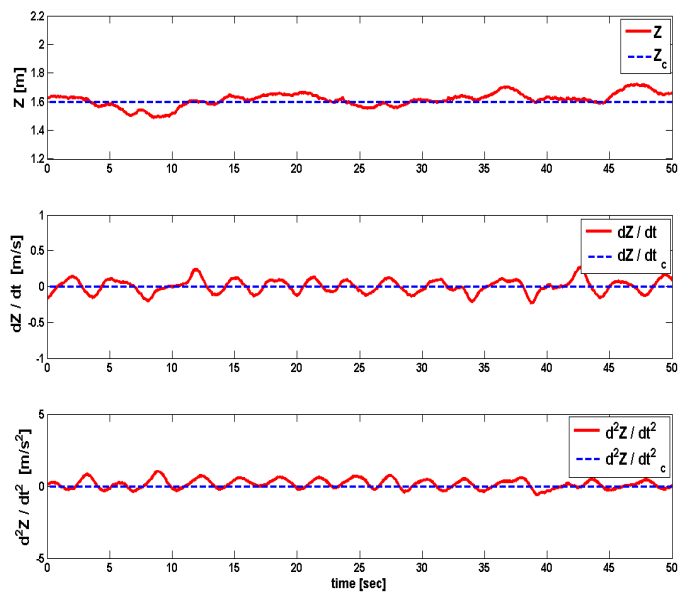

그림 22. 목표 추적 중 $Z$ 축 실험 결과 


\section{VI. 결 론}

본 연구에서는 움직이는 물체에 대한 추적 제 어기를 설계하였고, 이를 실험을 통해서 증명하 였다. 이를 위해서 시각 기반의 물체 인식 시스 템을 구성하였고, 접근성이 쉬운 상용 쿼드로터 플랫폼을 이용하였다.

제어기의 설계에 앞서, 신뢰성 있는 모델을 얻 기 위해서 예측오차기법을 통해서 모델을 추정하 였으며, 새로운 실험 데이터와 예측되어진 모델 과의 비교를 통해서 모델을 검증하였다.

이 추정된 모델은 실제로 제어 알고리즘이 돌 아가는 주기를 고려하여 이산화를 하고, $X, Y, Z$ 축으로 분리되어진 상태 공간 방정식 형태의 모 델을 구성하였다. 이를 기반으로 이산시간에서의 $\mathrm{LQR}$ 제어기를 설계하였으며, 실제 실험을 수행하 여 설계된 제어기 성능을 평가하였다.

그 결과는 $X, Y$ 축에서는 약 $\pm 0.15 \mathrm{~m}$, 고도는 $\pm 0.1 \mathrm{~m}$ 오차 영역 안에서 제어가 되었고, 0 으로 수렴하지 않고 계속 진동하는 경향이 나타났다. 이는 모델의 부정확성으로 인한 제어성능 저하가 아닌, 비전센서에서 계산된 $X, Y$ 값에 대한 정확 한 검증이 이루어지지 않아 나타난 결과로 볼 수 있으며, 이를 검증하는 실험이 수행되어져야 한 다. 또한 물체의 속도가 좀 더 빠르게 움직이는 상황에서의 제어기의 성능은 장담을 할 수 없다. 이는 비전 센서의 촬영 영역에 한계가 있으며, 기체 고정식의 비전 센서의 장착은 쿼드로터의 움직임이 클 때, 추적 대상이 인식이 되지 않을 수 있다는 문제점을 가지고 있으므로, 이를 추정 하는 알고리즘을 연구할 필요가 있다.

$$
\text { 후 기 }
$$

본 연구는 한국연구재단에서 지원하는 중견 연구자 지원 사업(2011-0016807)의 지원을 받아 수행하였습니다.

\section{참고문헌}

1) Pedro Castllo, Alejandro Dzul, Rogelio Lozano, "Real-Time Stabilization and Tracking of a Four-Rotor Mini Rotorcraft " IEEE trans Automat, vol.12 July 2004

2) Gabriel M. Hoffmann, Haomiao Huang, Steven L. Waslander, Claire J. Tomlin, "Quadr- otor Helicopter Flight Dynamics and Control: Theory and Experiment", AIAA Guidance, Navigation and Control Conference and Exhibit August 2007, Hilton Head, South Carolina

3) N. Michael, J. Fink, V. Kumar, "Cooperative manipulation and transportation with aerial robots", Robotics: Science and Systems, Seattle, 2009

4) Sergei Lupashin, Angela Schollig, Michael Sherback, Raffaello D'Andrea, "A Simple Learning Strategy for High-Speed Quadrocopter Multi-Flips", Robotics and Automation(ICRA), 2010 IEEE International Conference 3-7 May 2010, Anchorage, AK

5) AscTec Hummingbird with AutoPilot User's Manual, Ascending Technologies GmbH

6) CMUcam2 Guide, http://cmucam.org

7) TMS320F28335 DSCs Datasheet

8) Mario Valenti, Brett Bethke Gaston Fiore, Jonathan P. How, "Indoor Multi-Vehicle Flight Testbed for Fault Detection, Isolation, and Recovery", AIAA Guidance, Navigation, and Control Conference and Exhibit 21-24 August 2006, Keystone, Colorado

9) DS1401, Micro Autobox, dSPACE GmbH, http://www.dspaceinc.com

10) Ruesch, "Dynamics Identification \& Validation, and Position Control for a Quadrotor", Semester-Thesis, Eidgenossishce Te- chnische Hoschschule Zurich, 2010

11) Lennart Ljung, "System Identification, Theory for the User ", 2nd edition Prentice Hall

12) Lennart Ljung, "Prediction Error Estimation Methods", Circuits Systems Signal Processing, vol. 21, no. 1, pp. 11-21, 2002

13) Tomas McKelvey,"Relations Between Time Domain and Frequency Domain Prediction Error Methods" CONTROLSYSTEMS, ROBOTICS, AND AUTOMATION, Vol.V, EOLSS, 2009

14) Lennart Ljung, System Identification Toolbox, MathWorksInc, 1991.

15) Gene F. Franklin, J. David Powell, Abbas Emami-naeini, "Feed Control of Dynamic System", 4th edition Prentice Hall

16) 백수호, "무인항공기의 강건 비행경로 계획 및 유도 알고리즘의 HILS기반의 실험적 연구", 석사학위 논문, 세종대학교 항공우주공학과, 2008. 